\title{
(อ) OPEN ACCESS \\ Uncovering social structures and informational prejudices to reduce inequity in delivery and uptake of new molecular technologies
}

\author{
Sara Filoche (10 , ${ }_{1}^{1}$ Peter Stone, ${ }^{2}$ Fiona $\mathrm{Cram}_{1}{ }^{3}$ Sondra Bacharach, ${ }^{4}$ Anthony Dowell, \\ Dianne Sika-Paotonu, ${ }^{6}$ Angela Beard, ${ }^{7}$ Judy Ormandy ${ }_{1}^{8}$ Christina Buchanan, ${ }^{9}$ \\ Michelle Thunders, ${ }^{6}$ Kevin Dew ${ }^{10}$
}

For numbered affiliations see end of article.

\section{Correspondence to}

Dr Sara Filoche, University of Otago, Wellington 6242, New Zealand;

sara.filoche@otago.ac.nz

Received 26 July 2019

Revised 16 November 2019 Accepted 19 November 2019

Published Online First

7 January 2020
Check for updates

(C) Author(s) (or their employer(s)) 2020. Re-use permitted under CC BY-NC. No commercial re-use. See rights and permissions. Published by BMJ.

To cite: Filoche $S$, Stone $P$, Cram F, et al. J Med Ethics 2020;46:763-767.

\section{ABSTRACT}

Advances in molecular technologies have the potential to help remedy health inequities through earlier detection and prevention; if, however, their delivery and uptake (and therefore any benefits associated with such testing) are not more carefully considered, there is a very real risk that existing inequities in access and use will be further exacerbated. We argue this risk relates to the way that information and knowledge about the technology is both acquired and shared, or not, between health practitioners and their patients.

A healthcare system can be viewed as a complex social network comprising individuals with different worldviews, hierarchies, professional cultures and subcultures and personal beliefs, both for those giving and receiving care. When healthcare practitioners are not perceived as knowledge equals, they would experience informational prejudices, and the result is that knowledge dissemination across and between them would be impeded. The uptake and delivery of a new technology may be inequitable as a result. Patients would also experience informational prejudice when they are viewed as not being able to understand the information that is presented to them, and information may be withheld.

Informational prejudices driven by social relations and structures have thus far been underexplored in considering (in)equitable implementation and uptake of new molecular technologies. Every healthcare interaction represents an opportunity for experiencing informational prejudice, and with it the risk of being inappropriately informed for undertaking (or offering) such screening or testing. Making knowledge acquisition and information dissemination, and experiences of informational prejudice, explicit through sociologically framed investigations would extend our understandings of (in) equity, and offer ways to affect network relationships and structures that support equity in delivery and uptake.

\section{INTRODUCTION}

New molecular technologies hold the promise of great health gains, ${ }^{1}$ but also risk exacerbating health inequities if their delivery and uptake is not equitable. ${ }^{23}$ We argue that this risk is related to the way knowledge about a new technology is acquired, or not, by health practitioners and how, what or if health practitioners then communicate this information to their patients-that is, that the risk is associated with the occurrence of informational prejudice(s). ${ }^{45}$ Informational prejudice is an epistemic injustice-where an individual is not perceived as having the capacity to understand information by another individual, and this affects how, what and if information is shared between them. ${ }^{45}$ As such, informational prejudice is an experience that is inextricably linked to the social structure within which the prejudice has occurred, and that informational prejudice can be experienced by, and/or between practitioners, and/or by the patients they care for. In this paper, we discuss social relations, and ways to explore them, in knowledge and information acquisition and dissemination as drivers of (in)equitable implementation and uptake of new molecular technologies.

\section{Health inequities associated with genetic and genomic testing}

In many countries across the world, for Indigenous peoples, people of colour and for those living in areas of high deprivation, access to healthcare is inequitable, and health outcomes poorer when compared with the dominant and wealthier population of that country. ${ }^{67}$ As new molecular technologies are becoming more widely adopted into routine practice, there is emerging evidence that access to, and consequently benefit of, molecular technologies are inequitable. ${ }^{8-14}$ For example, despite a known familial risk having been established, African-American women are still less likely to be referred for genetic screening for breast cancer-with some known drivers to this inequity being their healthcare practitioners and the wealth (or not) of the area where the clinic is situated. ${ }^{911}$ African-American women are also more likely than American women of European descent to receive a result of a variant of unknown significance when they have undergone screening for the presence of BRCA1/2 variants associated with breast and ovarian-related cancers. ${ }^{15}$ Variants of unknown significance are higher in a number of other cancers for people of other non-European ethnicities. ${ }^{14}$ In essence, this means for those people who receive a result of variant of unknown significance, there is limited (if no) benefit from 'personalised medicine', and as consequence, the potential for driving inequities further is very real. Inequity in delivery and uptake has also been linked to how knowledgeable the healthcare practitioner is about a particular test-with some healthcare practitioners never making referrals for further genetic or genomic testing or screening. ${ }^{8}$ For Indigenous populations, 
inequity is compounded because the healthcare service can fail to meet their health needs due to lack of cultural responsiveness. ${ }^{16}$ Although there are moves to create more culturally responsive services (eg, by having interpreters and including cultural caretakers who act as intermediaries/navigators between the clinic and family(ies)), ${ }^{17}$ these initiatives progress at a slower pace than the technologies they are chasing.

\section{Social view of healthcare, informational prejudices and (in) equity in delivery and uptake of a new molecular technology}

A healthcare system can be viewed as a complex social network comprising individuals with different worldviews, hierarchies, professional cultures and subcultures and personal beliefs, both of those giving and receiving care. ${ }^{18} 19$ Professional cultures and values are often established during training, with socialisation processes in the 'classroom' reinforcing common values, and the language of each profession. ${ }^{18}$ With increasing specialisation comes further immersion into the culture of a profession. ${ }^{4}$ Epistemology is our way of knowing and our views of knowledge are constructed through our worldview (the lens through which we see and experience the world). ${ }^{5}$ To the extent that different people see and experience the world through different lenses, with different interests and cultural frameworks, and the opportunity for epistemic injustice arises. An epistemic injustice is, "a wrong done to someone specifically in their capacity as a knower". 5 Epistemic injustices occur in healthcare contexts as a result of a variety of factors, for example, diagnostic practices and healthcare policies, but the one salient for our purposes is informational prejudice. ${ }^{45}$ Informational prejudice occurs when a person or group is "prejudicially judged to lack the ability to provide information relevant in a given context" 45 and they may or may not receive the information they should. When healthcare practitioners are not perceived as knowledge equals, they would experience informational prejudices, and the result is that knowledge dissemination across and between them would be impeded. $^{20}$ The uptake and delivery of a new technology may be inequitable as a result. For example, a healthcare practitioner may hold the belief that the science and associated application of genetic testing is a specialist topic, and therefore decide to restrict knowledge dissemination to maintain a position as an 'expert'. This would exacerbate existing inequities around access to testing and limit adoption of the new technology, especially if a 'lower status' group of health practitioners is impeded from accessing technological knowledge and the technology itself. Informational prejudice would also play out between practitioners and patients, where assumptions are made about a patient's ability to understand information and/or the cultural acceptability of the test for the patient and/or the patient's ability to pay for the test. The consequence is that a patient may not be enabled to make an informed testing choice. So while new molecular technologies hold the promise of great health gains, their uptake and delivery will be inequitable and existing health inequities will persist if knowledge acquisition and information dissemination are treated as if they are bereft of their social and cultural context.

\section{Uncovering the social and relational structures, and informational prejudices empirical evidence of uptake and delivery}

In order to explore knowledge acquisition and information dissemination in their social and cultural contexts in association with the adoption of new molecular technologies, we argue that a body of work comprising four investigative strands is needed; namely, social network analysis to elucidate and visualise social structure and function, exploration of how and why knowledge and information is disseminated among healthcare practitioners, empirical evidence on the level of diffusion of the innovation, and an epistemological inquiry of end-users' experiences of receiving or acquiring knowledge and information. These will now be considered in turn.

Social network analysis is a quantitative approach to analysing social relations, for example, network structure and roles in terms of actors (individual health professionals) and ties (the connections between them). ${ }^{20-23}$ With this analysis, the types and characteristics of the relationships between and across different professionals can be explored in great detail (table 1). ${ }^{20-23}$ A knowledge broker can be defined as a role that acts as a link between different groups and individuals within a system where they would not normally have a relationship with one another. The defining feature of such a role is to develop relationships and networks with, among, and between people and users of knowledge to facilitate the exchange of knowledge throughout this network and to build capacity to support evidence-based decision-making. In terms of adoption of new technology (eg, a new genetic test within a health system), a knowledge broker could be the link between the laboratory or company and other health professionals. Conceptually, they could also be viewed as opinion leaders or champions. ${ }^{20-22}$ Because this role is a prominent position within a network, due to the ability of knowledge brokers to manage the flow of information between various actors, ${ }^{20-22}$ identifying knowledge brokers would be a primary outcome measure requirement of the social network analysis, when exploring the adoption and/or use of a particular test(s). The various actors present in the network (eg, healthcare practitioners, ascertained at the start of the social network design process) would be asked to identify which members of the network share information about a particular test(s) with others. The role of a knowledge broker is identified through centrality analysis (ie, betweenness centrality), where the number of times an actor connects pairs of other actors who otherwise would not be able to reach one another (table 1). ${ }^{20-22}$ Other structural and relational information from the network analysis such as network density could also be explored as this measure relates to how well the network is co-ordinated. ${ }^{24}$ Dense networks are thought to be beneficial for the co-ordination of an activity among actors. However, a major disadvantage of these dense networks is that they can entrench a particular value system and norm. Social networks and structures can therefore reinforce existing informational prejudices, or they can make possible new social relations, which could break down or prevent them.

How and why knowledge is shared is an important consideration in the context of informational prejudices and their occurrence. Knowledge sharing is a fundamentally social phenomenon and inherently relational in nature. ${ }^{25}$ Relation models theory claims that people are fundamentally sociable and have certain motivations for sharing (or not) ${ }^{25}$ : communal sharing, authority ranking, equality matching and market pricing. For example, "How is knowledge perceived?" can be answered in four different ways - for communal sharing, the answer is: as a common resource, something for sharing; for authority ranking the answer is: as means to display power; for equality matching, the answer is: as a means of exchange for other knowledge; and for market pricing, the answer is: as a commodity which has a value and can be traded. ${ }^{25}$ Deciphering the motivations for information sharing could be garnered through in-depth interviews of knowledge brokers and other members as identified 
Table 1 Measures and key characterises used in social network analysis 20212324

\begin{tabular}{|c|c|}
\hline Global structure: measure & $\begin{array}{l}\text { Characteristic } \\
\text { Network structural analysis }\end{array}$ \\
\hline Cohesion & Describes the interconnectedness of actors in a network. There are three types of measures of cohesion: \\
\hline Distance & $\begin{array}{l}\text { Distance measures the number of ties that separate two actors. If two nodes are directly connected, the distance is one. If these two } \\
\text { nodes are separated by one node, the distance is two, and so on. }\end{array}$ \\
\hline Reachability & $\begin{array}{l}\text { Reachability defines the degree by which a node can be reached by other nodes. If a certain number are unreachable by some actors, it } \\
\text { means that the network is fragmented. Reachability corresponds to the number of steps maximally needed to reach from one node to } \\
\text { any other node in the network. }\end{array}$ \\
\hline Density & $\begin{array}{l}\text { Density is defined as the number of existing ties divided by the number of possible ties. Dense networks are thought to be good for } \\
\text { coordination of an activity among actors. However, the downside to having dense networks is that they can entrench a particular value } \\
\text { system and norm. }\end{array}$ \\
\hline Centrality & $\begin{array}{l}\text { The degree of centrality represents the number of ties an actor has. If an actor has many ties compared with other actors, this indicates } \\
\text { that this actor has a central position in the network. Centrality can also characterise the shape of a whole network. To analyse } \\
\text { centrality further, there are three measures: }\end{array}$ \\
\hline Degree centrality & Is the sum of all other actors who are directly to a particular actor. It signifies activity or popularity. \\
\hline Degree closeness & $\begin{array}{l}\text { Is based on the notion of distance. If an actor is close to all others in the network (a distance of no more than one), then that actor is } \\
\text { not dependent on any other actor to reach everyone in the network. }\end{array}$ \\
\hline Betweenness centrality & $\begin{array}{l}\text { Is the number of times an actor connects pairs of other actors, who otherwise would not be able to reach one another, and is an } \\
\text { indicator of the power that actor has in the network. }\end{array}$ \\
\hline Within structure: measure & Network pairwise (between-actor) analysis. \\
\hline Tie strength & Relates to the intensity of the connection between two actors. \\
\hline Embeddedness & $\begin{array}{l}\text { Is the extent to which network members share common peers, reflecting the number of neighbours that two connected members have } \\
\text { in common. }\end{array}$ \\
\hline Role and position: measure & $\begin{array}{l}\text { Characteristic } \\
\text { Network relational analysis }\end{array}$ \\
\hline Structural equivalence & Actors that have exactly the same ties to exactly the same others in a network. \\
\hline Regular equivalence & $\begin{array}{l}\text { Less formal than structural equivalence. Actors who are defined as being regularly equivalent have identical ties, but not necessarily to } \\
\text { identical others. }\end{array}$ \\
\hline Automorphic equivalence & $\begin{array}{l}\text { Automorphic equivalence asks if the whole network can be re-arranged, putting different actors at different nodes, but leaving the } \\
\text { relational structure or skeleton of the network intact. }\end{array}$ \\
\hline
\end{tabular}

from the network analysis, including any members which take a peripheral position.

In order to understand how 'successful' the network relations and structures are at enabling the adoption and delivery of a particular test, gathering empirical evidence such as the number of tests delivered, and by and for whom, over time are important metrics to include. Such metrics relate to diffusions of innovation theories, ${ }^{7627}$ such as Magnitude-the number of network members who have adopted the test, and the number of patients who have undergone such testing; Speed-the time to reach a certain level of penetration, has peak adoption rate been reached? Market share - to determine which particular test brands are being used. These metrics could then be correlated with those from the social network analysis to explore any interplay with social position, for example, equivalence (table 1). For example, we could interrogate the data to see whether all professionals (eg, general practitioners) are structurally equivalent through their knowledge acquisition/sharing; if they are, do they deliver the molecular test to the same extent, and to whom?

The above three investigative strands are embedded in pragmatic and quantitative paradigms and would only go part way to explaining and understanding how social structures and relationships associated with knowledge acquisition and information dissemination can drive inequity and uptake of a new molecular test. A necessary investigative strand would be one that entails a rich epistemological inquiry of end-users' experiences of receiving or acquiring knowledge and information in relation to the uptake and offer of a new molecular test. Having this information would enable the appropriate 'meaning making' or triangulation of these data as a whole. This piece of the investigation jigsaw is often overlooked, and by virtue of exclusion only serves to perpetuate epistemic injustice and occurrence of informational prejudice. Of accounts that have explored patient views, or understanding, of a given test (or aspects associated with genomic testing), the study question, and resultant analysis and description, often frames the patients as being the problem, and their level of understanding or views correlated with educational attainment, ethnicity and/or socioeconomic position (or lack thereof) ${ }^{28-32}$-further exacerbating epistemic injustices. Indeed, 'we' have a lack of understanding of what informed choice actually means to the people who are undergoing testing or screening, despite health policy(ies) and professional guidelines indicating that it is the responsibility of the practitioner to ensure people make an informed choice to decline, or agree to, testing. Enabling an informed choice in a genomic era is of paramount importance and significance, ${ }^{33}$ given the scope of conditions that can be screened for, and the implications surrounding storage of, and access to, and use of DNA information. ${ }^{3435} \mathrm{~A}$ rich epistemological investigation could be garnered through purposeful sampling and semistructured interviews with practitioners and patients who have experienced the phenomenon of informational prejudice in relation to knowledge acquisition of a new molecular test. For analysis, interpretative phenomenological analysis (IPA) would be a fitting analytical framework as it acknowledges the importance of the social and cultural context, including for Indigenous peoples. " ${ }^{36}$ "The aim of IPA is to uncover what a lived experience means to the individual through a process of in depth reflective inquiry... IPA (also) acknowledges that we are each influenced by the worlds in 
which we live in and the experiences we encounter". ${ }^{37}$ Incidences of testimonial and hermeneutical injustices could also be drawn out from the data, for example, by identifying where some patients may experience feeling subordinated to the authority of healthcare professionals. ${ }^{45}$ To minimise bias, it would be important that the analyses be blinded to sociodemographic information. When exploring the occurrence of informational prejudice, it is also important to be cognisant of the structural prejudices that may be at play. ${ }^{5}$ Such structural prejudices are often inflexible, and could include the time allocated for a consultation, because a practitioner may be limited by time constraints to be able to share information in the most appropriate way that is most likely to build a patient's health literacy.

Informational prejudices driven by social relations and structures have thus far been underexplored in considering (in) equitable implementation and uptake of new molecular technologies. Every healthcare interaction represents an opportunity for experiencing informational prejudice, and with it the risk of being inappropriately informed for undertaking (or offering) such screening or testing. ${ }^{20}$ In order to redress health inequities around these new technologies, we need to act fast, and with approaches that are framed sociologically - and which uphold the person that is the patient, at the centre.

\section{Author affiliations}

'Department of Obstetrics, Gynaecology and Women's Health and Department of Pathology and Molecular Medicine, University of Otago, Wellington, New Zealand 2Department of Obstetrics and Gynaecology, University of Auckland, Auckland, New Zealand

${ }^{3}$ Katoa Ltd, Auckland, New Zealand

${ }^{4}$ School of History, Philosophy, Political Science and International Relations, Victoria University, Wellington, New Zealand

${ }^{5}$ Department of Primary Health Care and General Practice, University of Otago Wellington, Wellington, New Zealand

${ }^{6}$ Department of Pathology and Molecular Medicine, University of Otago, Wellington, New Zealand

${ }^{7}$ Christchurch Obstetric Associates, Christchurch, New Zealand

${ }^{8}$ Department of Obstetrics and Gynaecology, University of Otago, Christchurch, New Zealand

${ }^{9}$ Faculty of Medical and Health Sciences, The University of Auckland, New Zealand

${ }^{10}$ School of Social and Cultural Studies, Victoria University, Wellington, New Zealand

Acknowledgements The authors would like to thank all the various colleagues that have engaged in the discussions about this work.

Contributors SF conceived the idea and led the writing. PS contributed to the development of the methods and writing. FC contributed to the development of the methods and writing. SB contributed to the development of the methods and writing. $A D$ contributed to the development of the methods and writing. DS-P contributed to the development of the methods and writing. $A B$ critically reviewed the drafts. JO critically reviewed the drafts. CB contributed to the development of the methods and writing. MT contributed to the development of the methods and writing. KD contributed to the development of the methods and writing.

Funding The authors have not declared a specific grant for this research from any funding agency in the public, commercial or not-for-profit sectors.

Competing interests None declared.

\section{Patient consent for publication Not required.}

Ethics approval The work discussed in this paper is theoretical, and not derived from any study that has involved practitioner or patient recruitment, nor any patient health information. This paper is intended to promote discussion for such work to be undertaken. Neither is there any contestable funding associated with this paper, as such we did not seek ethical approval.

Provenance and peer review Not commissioned; externally peer reviewed.

Data availability statement There are no data in this work

Open access This is an open access article distributed in accordance with the Creative Commons Attribution Non Commercial (CC BY-NC 4.0) license, which permits others to distribute, remix, adapt, build upon this work non-commercially, and license their derivative works on different terms, provided the original work is properly cited, appropriate credit is given, any changes made indicated, and the use is non-commercial. See: http://creativecommons.org/licenses/by-nc/4.0/.

\section{ORCID iD}

Sara Filoche http://orcid.org/0000-0002-0874-6494

\section{REFERENCES}

1 Chief Medical Officer. Annual report of the chief medical officer: generation genome 2016.

2 Lynch SA, Borg I. Wide disparity of clinical genetics services and EU rare disease research funding across Europe. J Community Genet 2016:7(2):119-26.

3 Robertson SP, Hindmarsh JH, Berry S, et al. Genomic medicine must reduce, not compound, health inequities: the case for hauora-enhancing genomic resources for New Zealand. N Z Med J 2018;131(1480):81-9.

4 Aronson J, Burgess D, Phelan SM, et al. Unhealthy interactions: the role of stereotype threat in health disparities. Am J Public Health 2013;103(1):50-6.

5 Carel H, Kidd IJ. Epistemic injustice in healthcare: a philosophial analysis. Med Health Care Philos 2014;17(4):529-40.

6 Marmot M, Allen J, Bell R, et al. WHO European review of social determinants of health and the health divide. Lancet 2012;380(9846):1011-29.

7 National Academies of Sciences, Engineering and Medicine Health and Medicine Division, Board on Population Health and Public Health Practice. Communities in action: pathways to health equity. Washington DC: National Academies Press (US), 2017

8 Hillman SC, Dale J. Genomics in general practice: generation genome. Br J Gen Pract 2017;67(665):540-1

9 Hinchcliff EM, Bednar EM, Lu KH, et al. Disparities in gynecologic cancer genetics evaluation. Gynecol Oncol 2019;153(1):184-91.

10 Davis BA, Aminawung JA, Abu-Khalaf MM, et al. Racial and ethnic disparities in Oncotype DX test receipt in a statewide population-based study. J Nat/ Compr Canc Netw 2017;15(3):346-54.

11 McCarthy AM, Bristol M, Domchek SM, et al. Health care segregation, physician recommendation, and racial disparities in BRCA1/2 testing among women with breast cancer. J Clin Oncol 2016;34(22):2610-8.

12 Shields AE, Burke W, Levy DE. Differential use of available genetic tests among primary care physicians in the United States: results of a national survey. Genet Med 2008;10(6):404-14.

13 Drake TM, Knight SR, Harrison EM, et al. Global inequities in precision medicine and molecular cancer research. Front Oncol 2018;8:346.

14 Ndugga-Kabuye MK, Issaka RB. Inequities in multi-gene hereditary cancer testing: lower diagnostic yield and higher VUS rate in individuals who identify as Hispanic, African or Asian and Pacific Islander as compared to European. Fam Cancer 2019;18(4):465-9.

15 Saulsberry K, Terry SF. The need to build trust: a perspective on disparities in genetic testing. Genet Test Mol Biomarkers 2013;17(9):647-8.

16 Morgan J, Coe RR, Lesueur R, et al. Indigenous peoples and genomics: starting a conversation. J Genet Couns 2019;28(2):407-18.

17 Port RV, Arnold J, Kerr D, et al. Cultural enhancement of a clinical service to meet the needs of Indigenous people; genetic service development in response to issues for New Zealand Māori. Clin Genet 2008;73(2):132-8.

18 Hall P. Interprofessional teamwork: professional cultures as barriers. J Interprof Care 2005;19(sup 1):188-96.

19 Walton MM. Hierarchies: the Berlin wall of patient safety. Qual Saf Health Care 2006;15(4):229-30.

20 Tasselli S. Social networks of professionals in health care organizations: a review. Med Care Res Rev 2014;71(6):619-60.

21 Hawe P, Webster C, Shiell A. A glossary of terms for navigating the field of social network analysis. J Epidemiol Community Health 2004;58(12):971-5.

22 Muller $E$, Peres $R$. The effect of social networks structure on innovation performance: a review and directions for research. Int J Res Mark 2019;36(1):3-19.

23 Vivienne K. Social network analysis and research with Māori collectives. MAl Review2010;3

24 Groenen CJM, van Duijnhoven NTL, Faber MJ, et al. Use of social network analysis in maternity care to identify the profession most suited for case manager role. Midwifery 2017:45:50-5.

25 Boer N-I, van Baalen PJ, Kumar K. The implications of different models of social relations for understanding knowledge sharing. In: Tsoukas $\mathrm{H}$, Mylonopoulos N, eds. Organizations as knowledge systems: knowledge, learning and dynamic capabilities London: Palgrave Macmillan UK, 2004: 130-53.

26 Valente TW. Social network thresholds in the diffusion of innovations. Soc Networks 1996;18(1):69-89.

27 Valente TW. Diffusion of innovations. Genet Med 2003;5(2):69.

28 Oberg JA, Glade Bender JL, Cohn EG, et al. Overcoming challenges to meaningful informed consent for whole genome sequencing in pediatric cancer research. Pediatr Blood Cancer 2015;62(8):1374-80.

29 Tomlinson AN, Skinner D, Perry DL, et al. "Not tied up neatly with a bow": professionals' challenging cases in informed consent for genomic sequencing. J Genet Couns 2016;25(1):62-72.

30 Sanderson SC, Brothers KB, Mercaldo ND, et al. Public attitudes toward consent and data sharing in Biobank research: a large multi-site experimental survey in the US. Am J Hum Genet 2017;100(3):414-27. 
31 Lewis $\mathrm{C}$, Hill M, Skirton $\mathrm{H}$, et al. Development and validation of a measure of informed choice for women undergoing non-invasive prenatal testing for aneuploidy. Eur J Hum Genet 2016;24(6):809-16.

32 Blanchette PS, Spreafico A, Miller FA, et al. Genomic testing in cancer: patient knowledge, attitudes, and expectations. Cancer 2014;120(19):3066-73.

33 Horton R, Lucassen A. Consent and autonomy in the genomics era. Curr Genet Med Rep 2019:7(2):85-91.

34 Middleton A. Society and personal genome data. Hum Mol Genet 2018;27(R1):R8-13.
35 Beaton A, Hudson M, Milne M, et al. Engaging Māori in biobanking and genomic research: a model for biobanks to guide culturally informed governance, operational, and community engagement activities. Genet Med 2017; 19(3):345-51.

36 Cram F. Kaupapa Māori health research. Handbook of research methods in health and social sciences. Switzerland: Springer International Publishing, 2017.

37 Peat G, Rodriguez A, Smith J. Interpretive phenomenological analysis applied to healthcare research. Evid Based Nurs 2019;22(1):7-9. 